\title{
Persistence of Upper-Airway Symptoms During CPAP Compromises Adherence at 1 Year
}

\author{
Hanna-Riikka Kreivi MD PhD, Paula Maasilta MD PhD, and Adel Bachour MD PhD
}

BACKGROUND: The most common adverse effects of CPAP are related to the upper airways. We evaluated upper-airway symptoms before and after a CPAP trial as well as their effect on CPAP adherence. We also evaluated the effect of humidification added to CPAP therapy on upper-airway symptoms. METHODS: We followed for 1 y 536 subjects with obstructive sleep apnea scheduled consecutively for CPAP initiation. Subjects completed visual analog questionnaires on nasal stuffiness, rhinorrhea, and mouth dryness $(0=$ no symptoms, $100=$ severe symptoms $)$. RESULTS: Before CPAP initiation, mean nasal stuffiness score was $29.6 \pm 24.9$, rhinorrhea score was $16.0 \pm 21.7$, and mouth dryness score was $43.8 \pm$ 33.1. In subjects who quit CPAP treatment before the 1-y follow-up, the increase in rhinorrhea score during CPAP initiation was significant, 5.3 (95\% CI 0.5-9.5, $P=.02$ ), and in those using CPAP at $1 \mathrm{y}$, nasal stuffiness score and mouth dryness score decreased significantly during initiation, $-5.1(95 \% \mathrm{CI}-7.9$ to $-2.4, P<.001)$ and $-21.2(-25.5$ to $-17.4, P<.001)$. Mouth dryness score decreased significantly with CPAP regardless of humidification: change with humidification, -18.1 (95\% CI -22.1 to -14.3$), P<.001$; change without, $-10.5(95 \%$ CI -16.9 to -4.1$), P=.002$. Humidification also prevented the aggravation of rhinorrhea (change, -0.4 [95\% CI -2.6 to 1.9$], P=.75$ ) and alleviated nasal stuffiness (change -5.3 [95\% CI -7.8 to -2.6$], P<.001)$ with CPAP, whereas its absence induced a significant rise in symptom scores: change in rhinorrhea, 11.5 (95\% CI 7.1-16.7), $P<.001$; change in nasal stuffiness, 8.5 (95\% CI 3.9-13.5, $P<.001)$. CONCLUSIONS: The severity of upper-airway symptoms before CPAP does not predict CPAP use at $1 \mathrm{y}$, whereas CPAP non-users at $1 \mathrm{y}$ had smaller or no alleviation in symptom scores during initiation compared with those who continued CPAP treatment. Key words: CPAP; humidification; nasal stuffiness; mouth dryness; obstructive sleep apnea; upper-airway symptoms. [Respir Care 2016;61(5):652-657. @ 2016 Daedalus Enterprises]

\section{Introduction}

CPAP is the standard treatment for obstructive sleep apnea (OSA). ${ }^{1,2}$ CPAP effectively reduces snoring, apneas and hypopneas, thereby improving sleep quality and reducing daytime sleepiness as well as other symptoms. ${ }^{1-3}$ Adverse effects of CPAP treatment are mild and often

The authors are affiliated with the Department of Pulmonary Medicine, Heart and Lung Center, University of Helsinki and Helsinki University Hospital, Helsinki, Finland.

The authors have disclosed no conflicts of interest.

All authors contributed equally to this work.

Supplementary material related to this paper is available at http:// www.rcjournal.com. related to the upper airways. ${ }^{4,5}$ Nevertheless, these adverse effects can cause patients discomfort and even lead to treatment cessation. ${ }^{6,7}$ Previously, upper-airway complaints, especially rhinorrhea and sneezing, were assumed to increase during CPAP treatment. ${ }^{6}$ Recently, however, we evaluated the nasal symptoms of 385 subjects before CPAP initiation and 2 months after and found that upperairway symptoms related to dry mucosa seemed to decrease during CPAP treatment. ${ }^{8}$ In that previous study,

\footnotetext{
Correspondence: Hanna-Riikka Kreivi MD PhD, Department of Pulmonary Medicine, HUH Heart and Lung Center, University of Helsinki and Helsinki University Hospital, Haartmaninkatu 4, PO Box 372, FIN-00029 HUS, Helsinki, Finland. E-mail: hanna-riikka.kreivi@ hus.fi.
}

DOI: $10.4187 /$ respcare. 04113 
subjects received no humidification devices, whereas symptomatic subjects received topical medication (steroids and saline). Several studies have shown that heated humidification can effectively reduce upper-airway symptoms during CPAP treatment, ${ }^{9-12}$ but the effect of humidification on CPAP adherence remained unclear. Some studies have shown that objectively measured adherence increases with humidification, ${ }^{10,13}$ whereas other studies have shown that adding humidification to the treatment fails to improve CPAP adherence despite a reduction in upper-airway symptoms. ${ }^{12-14}$

One could speculate that the early addition of humidification alleviates patients' symptoms and may ameliorate long-term CPAP adherence. In this study, we added a humidification device for all of our symptomatic subjects. The aim of this study was to evaluate upper-airway symptoms before and after a CPAP trial as well as their effects on CPAP adherence by following the subjects for $1 \mathrm{y}$. We also aimed to describe the effect of adding humidification to CPAP therapy on upper-airway symptoms.

\section{Methods}

\section{Subjects}

We followed for 1 y 536 consecutive OSA subjects starting their CPAP treatment at the Sleep Unit at the Helsinki University Central Hospital, a tertiary sleep apnea referral hospital, between May 2010 and December 2012. The subjects were admitted to our sleep unit for CPAP initiation. All subjects had previously undergone an American Academy of Sleep Medicine type III (Embletta, EMBLA, ResMed, San Diego, California) sleep study showing an apnea and hypopnea index of $>5 / \mathrm{h}$ and suffered from daytime sleepiness.

All subjects had received information about CPAP therapy from a physician specializing in sleep medicine and agreed to be scheduled for a few days' CPAP trial. Subjects underwent CPAP initiation at home or at the hospital. At home, titrations were performed for a mean period of $4 \pm 2$ nights with the ResMed Autoset CPAP device (ResMed, San Diego, California) as described earlier. ${ }^{15}$ We set the pressure between $4 \mathrm{~cm} \mathrm{H}_{2} \mathrm{O}$ and a maximum of $20 \mathrm{~cm} \mathrm{H}_{2} \mathrm{O}$, and a ResLink (ResMed, San Diego, California) device with a pulse oximeter was attached to the device to monitor oxygen saturation during the CPAP trial. For subjects with reduced mobility or restricted learning ability, CPAP initiation was done at the sleep unit with the Autoset CPAP device. The cardiorespiratory sleep study device Embla N7000 (ResMed, San Diego, California) served to monitor the subjects at the Sleep Unit during automatic titration. Subjects were offered all types of CPAP

\section{QUICK LOOK}

\section{Current knowledge}

The most common CPAP adverse effects are related to the upper airways, and can cause patient discomfort and even lead to treatment cessation.

\section{What this paper contributes to our knowledge}

Subjects had frequent upper-airway symptoms prior to CPAP treatment, and the severity of symptoms before CPAP initiation did not predict long-term CPAP use. Mouth dryness decreased significantly with CPAP treatment regardless of humidification. The addition of heated humidification reversed the tendency of nasal stuffiness and rhinorrhea to worsen with CPAP treatment. We also showed that CPAP non-users at $1 \mathrm{y} \mathrm{had}$ no alleviation or a smaller alleviation in symptom scores during initiation compared with those who continued CPAP treatment at the $1-y$ follow-up.

interfaces before starting CPAP and later when needed. Masks were adjusted individually to be accepted by the subject, to achieve maximum comfort, and to ensure the absence of air leak. No mask switching occurred during the few days' CPAP trial. Moreover, we considered a trial successful if a subject was willing to continue CPAP treatment at home. After a successful trial, a 3-month and a 1-y follow-up visit were scheduled. The Research and Ethics Committee at our hospital approved the study protocol (38/2011, M101060027).

Three outcome variables related to the upper-airway symptoms were measured in this study. We used a subjective questionnaire method graded from no symptoms to severe symptoms. The subjects completed our routine selfreported visual analog questionnaire $(0=$ no symptoms, $100=$ severe symptoms) inquiring about their morning nose stuffiness, morning mouth and throat dryness, and morning rhinorrhea (see the supplementary materials at http://www.rcjournal.com) before and after a few nights' CPAP trial. To all subjects who had used nasal decongestants during the CPAP trial, we assigned a nasal stuffiness score of 100 .

The subjects were not randomly designated for humidification, but a sleep nurse was instructed to add heated humidification to the treatment during the CPAP trial if the subject reported any upper-airway symptoms that disturbed his or her daily life or if the subject regularly used nasal steroids. Humidification was later administered if a subject's upper-airway symptoms worsened with CPAP initiation. 
Table 1. Characteristics of All Subjects and According to Decongestant Use

\begin{tabular}{lccc}
\hline \hline \multirow{2}{*}{ Characteristics } & All & \multicolumn{2}{c}{ Decongestant } \\
\cline { 3 - 4 } & $(N=536)$ & $\begin{array}{c}\text { Users } \\
(n=35)\end{array}$ & $\begin{array}{c}\text { Non-users } \\
(n=501)\end{array}$ \\
\hline Age, y & $55 \pm 12$ & $52 \pm 10$ & $56 \pm 12$ \\
Body mass index, $\mathrm{kg} / \mathrm{m}^{2}$ & $32 \pm 7$ & $30 \pm 7$ & $32 \pm 7$ \\
Apnea-hypopnea index & $33 \pm 22$ & $39 \pm 26$ & $33 \pm 21$ \\
Oxygen desaturation (4\%) index & $29 \pm 22$ & $33 \pm 25$ & $29 \pm 22$ \\
$\mathrm{~S}_{\mathrm{pO}_{2}}, \%$ & $93 \pm 4$ & $92 \pm 4$ & $93 \pm 3$ \\
Epworth Sleepiness Scale & $9 \pm 3$ & $9 \pm 5$ & $9 \pm 4$ \\
\hline Data are shown as mean $\pm \mathrm{SD}$. & & & \\
\hline
\end{tabular}

\section{Statistical Analysis}

The data are presented as means $\pm \mathrm{SD}$ or as $n(\%)$. The most important outcomes are given with $95 \%$ CIs. The comparisons between the groups were made by a $t$ test, bootstrapped type $t$ test, or chi-square test, when appropriate. The changes within groups were analyzed by applying a bootstrapped type $t$ test. The changes of symptom scores between groups were made by bootstrap type analysis of covariance, using baseline measurement as a covariate. The bootstrap method is significantly helpful when the theoretical distribution of the test statistic is unknown or in the case of violation of the assumptions (eg, nonnormality). The normality of the variables was tested by using the Shapiro-Wilk W test. No adjustment was made for multiple testing. The STATA 14.0 (StataCorp, College Station, Texas) statistical package was used for the analyses.

\section{Results}

Altogether, 536 subjects underwent CPAP initiation that lasted a mean of $4 \pm 2 \mathrm{~d}$. Subjects' characteristics are described in Table 1. During initiation, 35 subjects (7\%) had used a decongestant at least once. We noticed no significant differences between groups of decongestant users and non-users (Table 1). At the 3-month follow-up visit, 455 subjects (85\%) continued CPAP treatment, and their average CPAP use was $3.5 \pm 2.4 \mathrm{~h}$, and at the $1-\mathrm{y}$ follow-up, 305 subjects (57\%) continued CPAP treatment, and their average CPAP use was $4.4 \pm 2.3 \mathrm{~h}$. Of users at the 1-y follow-up, 179 (59\%) used CPAP for $>4 \mathrm{~h} / \mathrm{d}$.

\section{Humidification}

We initially provided 417 (78\%) subjects with heated humidification: another 30 (6\%) subjects received humidification later. A total of 16 subjects (3\%) refused the
Table 2. CPAP Users at 3-Month and 1-Year Follow-Up Visits According to Humidification Use

\begin{tabular}{lccc}
\hline \hline \multicolumn{1}{c}{ CPAP Users } & $\begin{array}{c}\text { With } \\
\text { Humidification } \\
(n=417)\end{array}$ & $\begin{array}{c}\text { Without } \\
\text { Humidification } \\
(n=119)\end{array}$ & $P$ \\
\hline At 3-mo follow-up & $355(85)$ & $100(84)$ & .77 \\
At 1-y follow-up & $238(57)$ & $67(56)$ & .84 \\
\hline Data are shown as $n(\%)$. & & & \\
\hline
\end{tabular}

Table 3. Upper-Airway Symptoms Before and After CPAP Initiation

\begin{tabular}{lcccr}
\hline \multicolumn{1}{c}{ Symptoms } & Baseline & After Initiation & Change & \multicolumn{1}{c}{$P$} \\
\hline Nasal stuffiness & $29.6 \pm 24.9$ & $27.4 \pm 25.8$ & $-2.3(-4.6$ to 0.2$)$ & .060 \\
Rhinorrhea & $16.0 \pm 21.7$ & $18.2 \pm 24.7$ & $2.2(0.3-4.4)$ & .040 \\
Mouth dryness & $43.8 \pm 33.1$ & $27.4 \pm 25.8$ & $-16.5(-19.8$ to -12.9$)$ & $<.001$
\end{tabular}

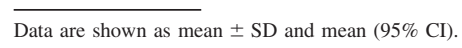

humidification offered, and 73 subjects (14\%) required no humidification at all. There was no difference in CPAP adherence at the 3-month and 1-y follow-up visits between the subject group using CPAP with and without humidification (Table 2).

\section{Upper-Airway Symptoms Before and After CPAP Initiation}

Upper-airway symptom severity scores before and after CPAP initiation are presented in Table 3. After CPAP initiation, the mouth dryness score decreased significantly, whereas a modest increase was seen in mean rhinorrhea score (Table 3). There was a significant difference between all symptom severity scores before CPAP initiation according to humidification use versus no humidification use $(P<.001)$ (Fig. 1). The changes in severity scores after CPAP initiation are presented in Figure 1. In the humidification group, nasal stuffiness and mouth dryness scores decreased significantly, and in the no-humidification group, mouth dryness decreased, whereas nasal stuffiness and rhinorrhea scores increased significantly (Table 4). The changes in symptom severity scores between humidification and no-humidification group after adjusted prior values were significant for the rhinorrhea score $(P=.01)$ and mouth dryness score $(P=.02)$.

\section{Upper-Airway Symptoms and CPAP Use at 1 Year}

There was no statistical difference in baseline upperairway symptom scores before CPAP initiation between the subjects who continued CPAP treatment at $1 \mathrm{y}$ (users) 

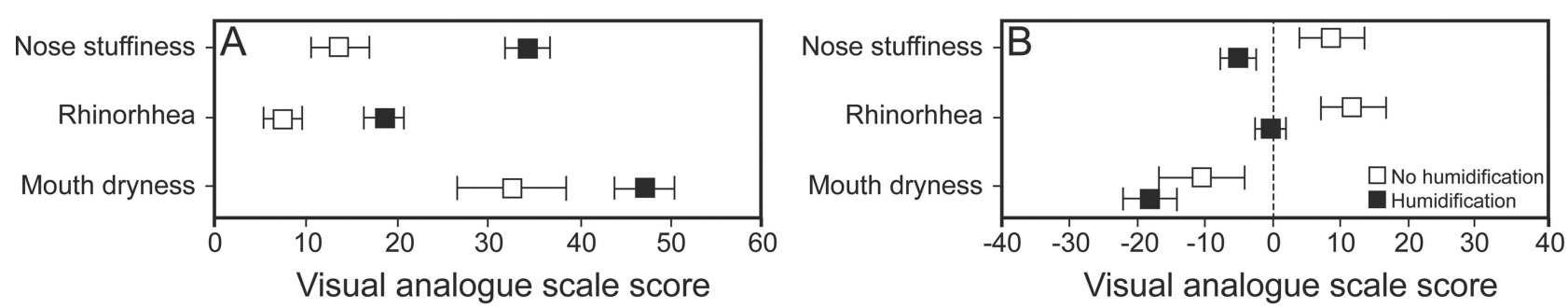

Fig. 1. Upper-airway symptom severity before CPAP (A) and change after CPAP initiation (B) in subjects with and without humidification using a visual analogue scale score: 0 = no symptoms, 100 = severe symptoms. Error bars represent $95 \% \mathrm{Cl}$.

Table 4. Change in Upper-Airway Symptom Scores Before and After CPAP Initiation

\begin{tabular}{lccccr}
\hline \hline \multirow{2}{*}{ Symptoms } & \multicolumn{2}{c}{$\begin{array}{c}\text { With } \\
\text { Humidification }\end{array}$} & & \multicolumn{2}{c}{$\begin{array}{c}\text { Without } \\
\text { Humidification }\end{array}$} \\
\cline { 2 - 3 } \cline { 5 - 6 } \cline { 5 - 6 } Change & $P$ & & Change & $P$ \\
\hline Nasal stuffiness & $-5.3(-7.8$ to -2.6$)$ & $<.001$ & & $8.5(3.9-13.5)$ & $<.001$ \\
Rhinorrhea & $-0.4(-2.6$ to 1.9$)$ & .75 & $11.5(7.1-16.7)$ & $<.001$ \\
Mouth dryness & $-18.1(-22.1$ to -14.3$)$ & $<.001$ & $-10.5(-16.9$ to -4.1$)$ & .002 \\
& & & & & \\
\hline Data are shown as mean $(95 \% \mathrm{CI})$. & & & & \\
\hline
\end{tabular}

and those who had quit the treatment before the 1-y follow-up visit (non-users) (Fig. 2). In the non-user group, the increase in the rhinorrhea score during CPAP initiation was significant, and in the CPAP user group, the nasal stuffiness score and mouth dryness score decreased significantly (Table 5). The changes in severity scores between humidification and no-humidification group after the adjusted prior value were significant for nasal stuffiness $(P<.001)$, mouth dryness $(P<.001)$, and rhinorrhea score $(P=.041)$.

\section{Discussion}

In this prospective follow-up study, we show that the severity of upper-airway symptoms before CPAP does not predict CPAP use at $1 \mathrm{y}$, whereas CPAP non-users at $1 \mathrm{y}$ had smaller or no alleviation in symptom scores during initiation compared with those who continued CPAP treatment. Mouth dryness decreased during CPAP treatment regardless of the use of humidification. In the no-humidification group, nasal stuffiness and rhinorrhea increased significantly, whereas in the humidification group, nasal stuffiness scores decreased, and rhinorrhea scores showed no change.

Many OSA patients already exhibit upper-airway symptoms before receiving any treatment for OSA. ${ }^{16}$ The adverse effects of CPAP therapy are local mainly to the upper airways but may cause patients substantial discomfort, ${ }^{5,6,8,17}$ even leading to treatment cessation. This study confirms one of our previous findings, ${ }^{8}$ that CPAP treat- ment alleviates mouth dryness in OSA subjects. We may speculate that mouth dryness usually decreases during CPAP treatment because patients no longer need to gasp for air through their mouth at the end of apnea events. However, some patients may develop a unidirectional air leak through the mouth, thereby causing worsening in mouth dryness. ${ }^{18,19}$ Meanwhile, the persistence of mouth dryness with CPAP therapy may also stem from other diseases or from adverse effects of medications, ${ }^{20}$ or we assume that it may even signal insufficient CPAP pressure levels, causing apneas and hypopneas to persist.

The use of heated humidification with CPAP blocks the tendency of nasal stuffiness to worsen during CPAP treatment. Ryan et al ${ }^{12}$ have previously shown that adding humidification to CPAP therapy reduces the frequency of nasal symptoms. We noticed that the severity of nasal symptoms before the CPAP trial has no influence on longterm CPAP use, whereas those subjects who had no alleviation or only small alleviation of nasal symptoms during CPAP initiation quit CPAP treatment more often.

In our clinic, we add humidification to CPAP treatment when the patients complain of nasal symptoms, even moderate ones. We also add humidification if the patient uses nasal steroids. This explains the high percentage (77\%) of humidification used in our study population. In the nohumidification group, scores for nasal stuffiness and rhinorrhea were significantly higher, whereas with humidification, they remained unchanged. This result calls into question whether all CPAP patients should receive humidification, since it is both bulky and costly. Perhaps such decisions are best made individually. Nevertheless, our results presume that failing to provide humidification to patients with initial nasal symptoms may lead to low CPAP adherence or even CPAP cessation. Subjects with and without humidification were supervised closely for any upperairway symptoms; therefore, the role of the effect of expectation (Hawthorne effect), if any, would have been a minor one, in the evaluation on upper-airway symptoms in the humidification group.

We acknowledge some limitations of the study. First, we did not randomize the use of humidification. Rather, we administered humidification according to individual 

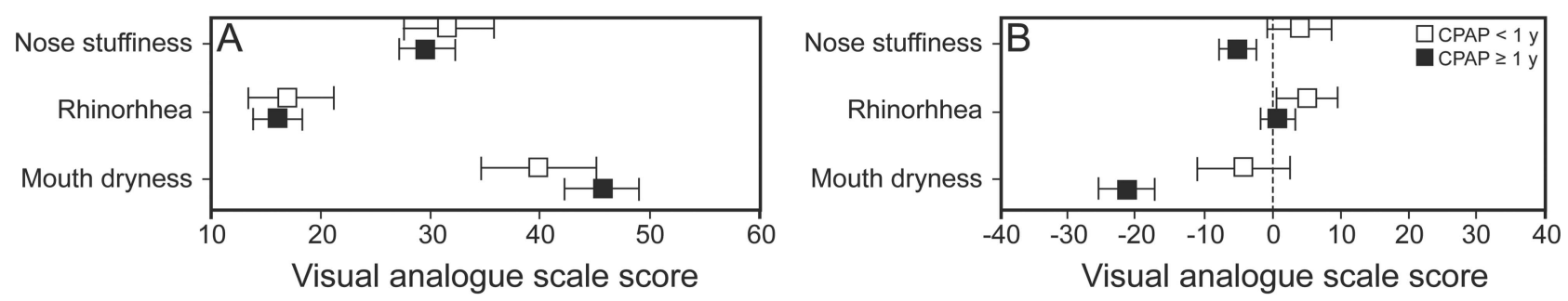

Fig. 2. Upper-airway symptom severity before CPAP (A) and change after CPAP initiation (B) in subjects using CPAP for different lengths of time using a visual analogue scale score: $0=$ no symptoms, $100=$ severe symptoms. Error bars represent $95 \% \mathrm{Cl}$.

Table 5. Change in Upper-Airway Symptom Scores in Subjects Not Continuing CPAP Use at 1-Year Follow-Up (Non-Users) and Those Continuing CPAP at 1-Year Follow-Up (Users)

\begin{tabular}{|c|c|c|c|c|}
\hline \multirow{2}{*}{ Symptoms } & \multicolumn{2}{|l|}{ Non-Users } & \multicolumn{2}{|l|}{ Users } \\
\hline & Change & $P$ & Change & $P$ \\
\hline Nasal stuffiness & $-5.3(-7.8$ to -2.6$)$ & $<.001$ & $8.5(3.9-13.5)$ & $<.001$ \\
\hline Rhinorrhea & $-0.4(-2.6$ to 1.9$)$ & .75 & $11.5(7.1-16.7)$ & $<.001$ \\
\hline Mouth dryness & $-18.1(-22.1$ to -14.3$)$ & $<.001$ & $-10.5(-16.9$ to -4.1$)$ & .002 \\
\hline
\end{tabular}

symptoms, so we could not confirm the effect of humidification on CPAP adherence. Second, we included decongestant users in the analysis of nasal symptoms, knowing that this may have slightly overestimated our nasal symptom scores. Meanwhile, we presumed that nasal stuffiness disturbed CPAP therapy at least enough to compel the subjects to request medications for it. Third, we recognize myriad other factors and adverse effects that impact adherence, but we believe that these do not change the conclusions for our results because our subjects were consecutive and all received the same instructions and the same CPAP device. Moreover, we have previously shown that the satisfaction rate with the CPAP interface does not affect daily CPAP use. ${ }^{21} \mathrm{We}$ do recognize that the CPAP interface may affect the severity of upper-airway symptoms. Effectively, in this study, no mask switching occurred during the CPAP trial, excluding any effects of CPAP interfaces on the modifications of the upper-airway symptoms with CPAP.

\section{Conclusions}

Upper-airway symptoms before CPAP initiation show no correlation with CPAP adherence at $1 \mathrm{y}$. Mouth dryness decreases significantly with CPAP treatment. Moreover, the addition of heated humidification reverses the tendency of nasal stuffiness and rhinorrhea to worsen with CPAP treatment. Finally, we showed that CPAP non-users at $1 \mathrm{y}$ had no alleviation or had smaller alleviation in symptom scores during initiation compared with those who continued CPAP treatment at the 1-y follow-up.

\section{ACKNOWLEDGMENTS}

We thank Leena Petman RN, Jaana Wörlin RN, and Anne Hildén RN for assistance in collecting the data.

\section{REFERENCES}

1. Giles TL, Lasserson TJ, Smith BH, White J, Wright J, Cates CJ. Continuous positive airways pressure for obstructive sleep apnoea in adults. Cochrane Database Syst Rev 2006;(3):CD001106.

2. Kakkar RK, Berry RB. Positive airway pressure treatment for obstructive sleep apnea. Chest 2007;132(3):1057-1072.

3. McDaid C, Durée KH, Griffin SC, Weatherly HL, Stradling JR, Davies RJ, et al. A systematic review of continuous positive airway pressure for obstructive sleep apnoea-hypopnoea syndrome. Sleep Med Rev 2009;13(6):427-436.

4. Meslier N, Lebrun T, Grillier-Lanoir V, Rolland N, Henderick C, Sailly JC, Racineux JL. A French survey of 3,225 patients treated with CPAP for obstructive sleep apnoea: benefits, tolerance, compliance and quality of life. Eur Respir J 1998;12(1):185-192.

5. Pépin JL, Leger P, Veale D, Langevin B, Robert D, Lévy P. Side effects of nasal continuous positive airway pressure in sleep apnea syndrome: study of 193 patients in two French sleep centers. Chest 1995;107(2):375-381.

6. Brander PE, Soirinsuo M, Lohela P. Nasopharyngeal symptoms in patients with obstructive sleep apnea syndrome: effect of nasal CPAP treatment. Respiration 1999;66(2):128-135.

7. Baltzan MA, Elkholi O, Wolkove N. Evidence of interrelated side effects with reduced compliance in patients treated with nasal continuous positive airway pressure. Sleep Med 2009;10(2):198-205.

8. Kreivi HR, Virkkula P, Lehto J, Brander P. Frequency of upper airway symptoms before and during continuous positive airway pressure treatment in patients with obstructive sleep apnea syndrome. Respiration 2010;80(6):488-494.

9. Martins De Araújo MT, Vieira SB, Vasquez EC, Fleury B. Heated humidification or face mask to prevent upper airway dryness during continuous positive airway pressure therapy. Chest 2000;117(1):142147.

10. Massie CA, Hart RW, Peralez K, Richards GN. Effects of humidification on nasal symptoms and compliance in sleep apnea patients using continuous positive airway pressure. Chest 1999;116(2):403408.

11. Neill AM, Wai HS, Bannan SP, Beasley CR, Weatherall M, Campbell AJ. Humidified nasal continuous positive airway pressure in obstructive sleep apnoea. Eur Respir J 2003;22(2):258-262.

12. Ryan S, Doherty LS, Nolan GM, McNicholas WT. Effects of heated humidification and topical steroids on compliance, nasal symptoms, and quality of life in patients with obstructive sleep apnea syndrome using nasal continuous positive airway pressure. J Clin Sleep Med 2009;5(5):422-427. 


\section{UpPer-Airway Symptoms During CPAP Compromise AdHerence}

13. Mador MJ, Krauza M, Pervez A, Pierce D, Braun M. Effect of heated humidification on compliance and quality of life in patients with sleep apnea using nasal continuous positive airway pressure. Chest 2005;128(4):2151-2158.

14. Worsnop CJ, Miseski S, Rochford PD. Routine use of humidification with nasal continuous positive airway pressure. Intern Med J 2010; 40(9):650-656.

15. Bachour A, Virkkala JT, Maasilta PK. AutoCPAP initiation at home: optimal trial duration and cost-effectiveness. Sleep Med 2007;8(7): 704-710.

16. Kreivi HR, Virkkula P, Lehto JT, Brander PE. Upper airway symptoms in primary snoring and in sleep apnea. Acta Otolaryngol 2012; 132(5):510-518
17. Lojander J, Brander PE, Ammälä K. Nasopharyngeal symptoms and nasal continuous positive airway pressure therapy in obstructive sleep apnoea syndrome. Acta Otolaryngol 1999;119(4):497-502.

18. Mortimore IL, Bradley PA, Murray JA, Douglas NJ. Uvulopalatopharyngoplasty may compromise nasal CPAP therapy in sleep apnea syndrome. Am J Respir Crit Care Med 1996;154(6 Pt 1):1759-1762.

19. Bachour A, Maasilta P. Mouth breathing compromises adherence to nasal continuous positive airway pressure therapy. Chest 2004;126(4): 1248-1254.

20. Guggenheimer J, Moore PA. Xerostomia: etiology, recognition and treatment. J Am Dent Assoc 2003;134(1):61-69.

21. Bachour A, Vitikainen P, Virkkula P, Maasilta P. CPAP interface: satisfaction and side effects. Sleep Breath 2013;17(2):667-672. 